Other physical methods in the treatment of psychoneuroses and psychoses include continued narcosis and partial loss of consciousness under light anaesthesia. The latter procedure is used for recovery of buried memories by hypnotic suggestion during the recovery period.

\section{Psychological Aspects of Disease}

But such methods are for the severest types of cases. The point which concerns all of us is the striking change from the materialistic outlook prevalent in my student days to the modern recognition of the psychological aspects of disease. On this let me quote Sir Francis Fraser, himself trained in the strictest sect oi organic medicine. Speaking of the criticism that the medical schools give too scientific a training and send men out knowing next to nothing of the care of patients or of the personal side of practice, he says: "I am sure it is a just criticism, but maintain that hospital practice is not 'too scientific'-it is not sufficiently scientific. . . . Treatment based on the deduction that one patient's inefficiency is due to family troubles is just as scientific as that based on $x$-ray evidence of duodenal ulcer in another patient. 'To say 'there is nothing the matter' because the physical examination, $x$-ray evidence, and laboratory tests fail to disclose a cause of the trouble is, on the other hand, unscientific. If there was more exact knowledge of how the material and mental surroundings of our patients affect their functions and activities ... clinical instruction would more nearly meet the needs of private practice, and it would be more scientific, not less."

This was written 10 years ago, and I am sure that the author would admit that since then it has been shown that the psychological factor plays a considerable part in the causation even of the organic lesion he selects-duodenal ulcer. And so the latest phase in the evolution of modern therapeutics is recognition of the psychosomatic factors in disease-thereby in a way completing the circle by a return to Aesculapius.

\section{Discarded Methods}

The path of this progress is littered on either side by discarded theories and practices. It is a chastening experience to turn over one's old case records. One suddenly realizes that some formerly favourite treatment has been completely forgotten. My belief is that we practise continually an almost unconscious revision, and in this way a consensus of opinion is reached: no one has openly attacked the treatment, perhapsit has just passed silently into oblivion. And I suspect that a scrutiny of past literature from manufacturing firms would show that they have found it advisable to cease making a good many formerly vaunted remedies.

On this matter Trousseau's advice to his students remains as true as on the day when it was spoken: "Always use the new remedies while they still have power to heal." How is it that people were formerly cured by Bulgarian soured milk or by Bulgarian belladonna and are no longer? How is it that the routine use of vaccines therapeutically is fading out while their prophylactic use is increasing? One could quote many such examples. I think that admirable clinician the late T. A. Ross supplied the explanation. He noted that his experience of the result of the Weir Mitchell treatment fell into three periods. In the first the results were excellent and in the second variable; the third group was a failure. Then he realized that in the first he himself firmly believed in the method, in the second he had come to doubt it, while in the third he had ceased to believe in it and used it only at the request of others. I had the opportunity of studying Sir Lauder Brunton's methods fairly closely nearly 50 years ago. I attributed his undoubted therapeutic successes to two things-he had a genuine and deep sympathy for human suffering, and he always felt sure that he knew the precise remedy-preferably a new one from Germany-which would exactly suit the individual patient.

\section{Conclusion}

Well, I hope I have been able to show that gradually and by painstaking effort the profession has come into possession of a much larger number of well-attested remedies than formerly, in which we can have enough confidence ourselves justifiably to inspire confidence in our patients. We have a much clearer view of the fundamental principles of therapeutics, and the present position is full of promise for the future, for the last 40 years have shown greater advance than all the preceding centuries. We have passed away from the ancient mixture of empiricism and magic, by way of pharmacology, to a biological and indeed a b.ochemical approach. The tree of healing can now draw sustenance from many roots. In its present state it is still a young growth; let us see to it that its development is healthy, strong, pruned, and, above all things, honest.

\section{SCABIES PROPHYLAXIS USING "TETMOSOL" SOAP \\ BY}

\section{KENNETH MELLANBY, Sc.D.}

Recently I described (Mellanby, 1944a) some experiments in which attempts were made to control scabies infection. Except where therapeutic treatment with benzyl benzoate was given to all members of a closed community the results were disappointing. Since that paper was written a new method of some promise has been described (Davey et al., 1944 ; Gordon et al., 1944), and the present article describes a further prophylactic trial.

Prof. R. M. Gordon and his colleagues, in conjunction with Imperial Chemicals (Pharmaceuticals) Ltd. and Unilever Ltd., have produced a soap with good cosmetic properties which contains $10 \%$ of "tetmosol" (i.e., tetraethylthiuram monosulphide). The use of this soap has been shown to kill Sarcoptes and thus to cure scabies, though as a therapeutic agent at a treatment centre it is less efficient than benzyl benzoate. It is, however, so simple to use that it seemed possible that its general issue to an infected population would prevent further transmission of the disease. Whereas these authors described the therapeutic effect of tetmosol soap. they expressed the belief that its greatest value would be found in its use as a prophylactic against scabies-a property which they had already proved in the case of animals.

For a satisfactory test of the prophylactic value of tetmosol soap it was necessary to have a population showing a high incidence of scabies and to ensure that the soap was used by all individuals. Furthermore, facilities must be available for examining all subjects before and after the period during which the soap was used, in order to assess the effect on the incidence of scabies. Such conditions were found in a large mental hospital. Scabies was endemic among the patients; and the staff, having had many difficulties in combating the disease, were only too willing to co-operate in an experiment which might alleviate the position. To assess the amount of scabies present before, during, and after the experiment would obviously take a great many hours of skilled examination, but fortunately I had available at the Sorby Research Institute sufficient trained staff to make this practicable.

These facilities being available, I wished to place them at the disposal of Prof. Gordon. He decided, however, that he would prefer me to take the responsibility for the experiment, though he placed his advice at my disposal and also helped with the experiment in a number of ways.

\section{Procedure}

Before the experiment started every patient in the hospital was inspected; tetmosol soap was then supplied to approximately half of them. The details of the experiment were explained to the hospital staff, but nothing was said to the patients, who simply accepted the soap provided (it was rather pleasanter to use than that ordinarily available). All other treatment of scabies, whether in the control or in the experimental group, was discontinued for the 11 weeks of the trial.

Examination of the patients was carried out by volunteers from the Sorby Research Institute; these men had themselves had prolonged experimental infections with scabies, and were fully familiar with finding and removing acari. The examinations were all made under the supervision of Mr. W. C. Bartley. During the initial examinations I also was present. and during 
the latter part of the experiment Prof. Gordon and his colleagues visited the hospital on a number of occasions. The hands and wrists of all patients were carefully scrutinized, and any suspicious lesion was examined with a lens. Whenever any signs suggesting scabies were noticed but when no mites were found on the hands and wrists, the elbows were examined. A patieht was said to have scabies only when a live mite was removed and demonstrated.

\section{Results of the Experiment}

The results of the exam nations, before and after the use of tetmosol soap, are included in the accompanying Table.

Table showing the Therapeutic and Prophylactic Effects of the Use of $10 \%$ Tetmosol Soap and of Unmedicated Soap over a Period of 11 Weeks on the Incidence of Scabies in an Infected Community

\begin{tabular}{|c|c|c|c|c|c|c|c|c|c|c|}
\hline \multirow[b]{3}{*}{ Treatment } & \multirow{3}{*}{$\begin{array}{l}\text { Total } \\
\text { Patients }\end{array}$} & \multicolumn{9}{|c|}{ Observation Periods } \\
\hline & & \multicolumn{3}{|c|}{$\begin{array}{l}\text { Start of } \\
\text { Experiment }\end{array}$} & \multicolumn{3}{|c|}{$\begin{array}{l}\text { After Six } \\
\text { Weeks }\end{array}$} & \multicolumn{3}{|c|}{$\begin{array}{l}\text { After Eleven } \\
\text { Weeks }\end{array}$} \\
\hline & & 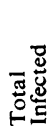 & 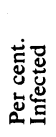 & $\begin{array}{l}\text { ü } \\
\text { Uू } \\
z \\
z \\
z\end{array}$ & 焉 & 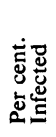 & 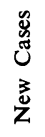 & 焉 & 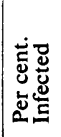 & $\begin{array}{l}\tilde{y} \\
\tilde{U} \\
\tilde{U} \\
z \\
z\end{array}$ \\
\hline $\begin{array}{l}\text { Tetmosol soap } \\
10 \%\end{array}$ & 705 & 93 & $13 \cdot 2$ & - & 9 & $1 \cdot 3$ & - & 9 & $1 \cdot 3$ & - \\
\hline $\begin{array}{l}\text { Unmedicated } \\
\text { soap }\end{array}$ & 1,213 & 18 & 1.5 & - & 26 & $2 \cdot 1$ & 8 & 42 & $3 \cdot 5$ & 24 \\
\hline
\end{tabular}

(a) Preliminary Examination.-Scabies was found to be much more common among the female than among the male patients; this agrees with the previous investigation (Mellanby, 1944b). Of the 1,101 women $106(9.6 \%)$ had scabies; while an additional $41(3.7 \%)$ showed some clinical signs of the disease but no live acari could be found-these cases were therefore omitted. The female patients lived in two separate blocks and in an admission hospital. For ease of administration and to ensure that only the right persons used the prescribed type of soap, one block containing 660 patients, of whom 89 $(13.5 \%)$ had scabies, was issued with tetmosol soap for each individual, while the admission hospital and another block which contained 441 patients, of whom $17(3.9 \%)$ had scabies, continued as before the experiment. The admission hospital had a varying population, and throughout the investigation no cases of scabies were found.

Only 5 of the 817 men $(0.6 \%)$ were infected. Four of these cases occurred in one ward, which contained 45 patients, and the soap was issued here. The remaining 772 male patients (containing only one case of scabies) served as a control. The final arrangement, therefore, was that a total of 705 patients, of whom $93(13.2 \%)$ were infected, were supplied with $10 \%$ tetmosol soap for their ablutions; while 1,213 patients, of whom $18(1.5 \%)$ were infected, continued to use ordinary soap.

(b) Examination After Six Weeks.-As the table shows, after six weeks the situation was greatly altered. Among the 705 patients using tetmosol soap the incidence of scabies had decreased from 13.2 to $1.3 \%$, and no new cases had occurred during this period; whereas in the control group, among 1,213 patients using ordinary soap, the incidence of scabies had increased from $1.5 \%$ to $2.1 \%$ and 8 new cases had been recorced.

(c) Final Examination After Eleven Weeks.-All the previous examinations were carefully carried out as described above, but for this final scrutiny particular care was taken to ensure that no cases were missed. Nine patients in the "tetmosol group" were found with scabies, none with heavy parasitic infections, and only three with mites on the hands. All of them showed signs of scabies at the original examination, made before the experiment started. Five of the nine cases (all with one or very few mites on the feet only) appeared clear at the six-weeks examination, but I believe that if the scope of the survey had allowed for a routine examination of other parts of the body on that date infection would have been discovered. Incidentally, three of these infected cases were bed patients who would have less access to the soap and whose feet might receive less lathering than the others. There were no new cases. A marked rise occurred in the control group, $3.5 \%$ of whom were now infected; the number of new cases had increased from 8 to 24 during the course of the experiment.

(d) Sensitivity to Tetmosol Soap.-Previous work (Gordon et al., 1944) had shown that, while most individuals could use tetmosol soap for long periods without any harm to the skin; a small proportion of cases might find it irritating. Of the 705 patients originally issued with the soap three only, all of them women, appeared to be sensitive. Within a few days of starting to use the soap they developed an erythematous rash in the areas washed. These women were withdrawn from the experiment and the rash disappeared rapidly. No person developed a sensitivity after the prolonged use of the soap. None of the 45 men showed any sensitivity.

\section{Discussion}

These experiments show that tetmosol soap can act as a very efficient means of controlling scabies. It not only prevents the disease from spreading but also cures the majority of those who use it for a few weeks. There seems no doubt that its general employment would rapidly eliminate scabies from a community. Where efficient centres for treatment exist, and where it would prove difficult to enforce the use of medicated soap, benzyl benzoate is much to be preferred as a therapeutic agent, but there must be many parts of the world where tetmosol soap. would have a wide field of application. It is obviously ideal for asylums and similar institutions; it would not be necessary for it to be used always, for an issue for a month or two each year (followed, the first year, by benzyl benzoate therapy for any few residual cases) would soon eliminate the disease.

The proportion of sensitive individuals unable to use tetmosol soap appears fortunately to be very small. They can be detected before any serious damage has been done to the skin, so there is little risk of causing dermatitis.

It may be noted that clothing and bedding were not disinfested in this experiment; the use of the soap alone successfully cured the majority of cases.

\section{Summary}

Patients in a mental hospital used tetmosol soap for a period of 11 weeks. Scabies, which was very prevalent at the start of the experiment, was almost entirely eliminated. Most cases were cured, and the spread of the disease was prevented.

These experiments could not have been carried out but for the advice and co-operation of Prof. R. M. Gordon, Prof. T. H. Davey, and $\mathrm{Mr}$. K. Unsworth. It is necessary to preserve the anonymity of the mental hospital concerned, but I wish to acknowledge that the success of the work was largely due to the help given by the medical superintendent and his staff. I am indebted to Mr. W. C. Bartley and to the men from the Sorby Research Institute for the care taken at the examinations. Also to Dr. H. A. Krebs, who had prior claim on the services of the volunteers during part of the period, for enabling them to continue with this work. The expenses of the investigation were met by the Medical Research Council, who also investigation were met by the Medical Research Council, who also
arranged for the supply of the soap through Imperial Chemicals (Pharmaceuticals) Ltd.

\section{REFERENCES}

Davey, T. H., Gordon, R. M., and Unsworth, K. (1944). Ann. trop. Med. Parasitol.,

38, 46.
Gordon, R. M., Davey, T. H., Unsworth, K., Hellier, F. F., Parry, S. C., and Alexander, J. R. B. (1944). British Medica! Journal, 1, 803

Mellanby, K. (1944a). Parasitclogy, 35, 197.

Mellan, (1944b). British Medical Journal, 1, 689.

A circular issued by the Department of Health for Scotland announces that more beds are now available for civilians in Scottish hospitals. In future there will be fewer beds reserved for the emergency hospital scheme in voluntary hospitals and local authority general hospitals. This should help to remove the difficulties which hospitals have found in providing for the needs of the civilian population. "In view of the altered war situation, which has already led to substantial reductions in the general Civil Defence Services," the circular states, "the Secretary of State considers that it is now possible to meet current and estimated future requirements in hospitals for Service casualties and other patients within the scope of the emergency hospital scheme with a smaller number of beds than have been reserved formerly for the scheme." In future, hospitals will be authorized to admit to their reserved beds other civilian patients as well as those in urgent need of treatment, when the immediate requirements of the emergency scheme permit this to be done. 